\title{
Predictors of Loco-Regional Recurrence and Cancer-Related Death after Breast Cancer Surgery
}

\author{
Stefano Rausei, MD, Francesca Rovera, MD, Gianlorenzo Dionigi, MD, FACS, \\ Deborah Tornese, MS, Anna Fachinetti, MS, Luigi Boni, MD, FACS, and \\ Renzo Dionigi, MD, FACS, FRCS (Hon. Edin.) \\ Department of Surgical Sciences, University of Insubria, Varese, Italy
}

Abstract: To determine which tumor-related factors might predispose the patient to loco-regional recurrence or death and the impact of these factors on the different types of events. We retrospectively analyzed the data of 1991 women between January 1998 and March 2010 for a first primary nonmetastatic breast cancer and treated with surgery and neoadjuvant/adjuvant therapy. The overall survival distribution was estimated using the Kaplan-Meier method. The prognostic impact of several factors on cumulative overall and loco-regional recurrence free survival was evaluated by univariate (logrank test) and multivariate analysis (Cox regression). At log-rank test, $\mathrm{pT}$, nodal status, histotype, grading, lymphangioinvasive growth, tumor diameter, estrogen receptors (ER) status, progesterone receptors (PR) status, expression of Ki67, and expression of Her2/neu had a prognostic value on loco-regional recurrence or overall survival. In the multivariate analysis grading remained the only independent predictor of loco-regional recurrences. With regard to overall survival, the Cox model selected grading along with nodal status and PR status. Loco-regional recurrences after breast cancer surgery are not frequent events. They are markers of tumor aggressiveness and predictor of an increased likelihood of cancer-related death. However, loco-regional recurrence and systemic tumor progression are partially independent events, since some prognostic factors differ.

Key Words: breast cancer, loco-regional recurrence, predictive factors

$\mathrm{T}$ oday, in minimally invasive surgery era, outcome of breast cancer patients after breast-conserving surgery seems better than outcome after mastectomy: actually, this effect is due to many early-stage diseases treated by conservative excision (1-4). However, while surgical procedure cannot be considered a prognostic factor for these patients, there is the need to detect reliable predictors of loco-regional recurrence, a marker of tumor aggressiveness linked to an increased risk of distant metastases and death (5-11). In fact, by identification of stronger pathologic and molecular predictors of loco-regional recurrence and more effective treatment strategies, the risk of local failure after breast surgery could decrease.

In this study, we analyzed data on 1991 women underwent surgery for breast cancer in order to determine which tumor-related factors might predispose

Address correspondence and reprints request to: Stefano Rausei, MD, Department of Surgical Sciences, University of Insubria, Viale L. Borri 57, 21100 Varese, Italy, or e-mail: s.rausei@libero.it.

DOI: $10.1111 /$ i.1524-4741.2010.01000.x

(c) 2010 Wiley Periodicals, Inc., 1075-122X/10

The Breast Journal, Volume 16 Suppl. 1, 2010 S29-S33 the patient to loco-regional recurrence or death and to determine the impact of these factors on the different types of events.

\section{PATIENTS AND METHODS}

\section{Study Population}

We retrospectively analyzed the data of 1991 women hospitalized at the University of Insubria Hospital in Varese between 1 January 1998 and 30 March 2010 for a first primary nonmetastatic breast cancer and treated with surgery and neo-adjuvant/adjuvant therapy. Women were usually followed up by physical examination every 6 months and mammography with breast ultrasound (US) annually; in symptomatic cases or when clinically indicated, bone scan, chest x-ray, liver US or computed tomography scan were carried out.

\section{Definitions of End Points}

Loco-regional recurrence was defined as recurrence in the original tumor bed or in the ipsilateral axillary, 
internal mammary or supraclavicular or infraclavicular nodes with the same histopathologic features of the primary tumor. Regarding to end point of death, we considered only deaths for breast cancer.

\section{Statistical Methods}

The overall survival distribution was estimated using the Kaplan-Meier method (12). New ipsilateral breast tumor, contralateral breast tumor, distant metastases onset and other nonbreast primary tumor were considered as censoring events for loco-regional recurrence free survival and death for other causes as censoring event for overall survival. In the absence of any of these events, the observation time was censored at the last follow-up visit. The prognostic impact of several factors on cumulative overall and loco-regional recurrence free survival was evaluated by log-rank test (13). Continuous variables were categorized according to the median value. In order to consider only tumorrelated factor, we excluded from analysis any patientand treatment-related factors. Variables reaching a $\mathrm{p}$ value $<0.1$ in the univariate analysis were regressed on the cause-specific hazard, using multivariate Cox proportional hazards model (14). The stepwise (backward elimination) procedure was used. The effect of each factor was expressed as hazard ratio (HR) with $95 \%$ confidence intervals (CIs). The proportional hazard assumption was controlled using goodness of fit tests. The statistical analysis was performed with SPSS software for Windows. All reported p-values were two-sided.

\section{RESULTS}

Median age was 61.1 years (range 24-96). Median follow-up was 53 months (range 1-148), with 44.7\% of patients having a follow-up $>5$ years. Table 1 shows the tumor-related factors of the cohort considered for analysis.

We observed 144 loco-regional recurrences and 55 cancer-related deaths as events, corresponding to a 5 -year cumulative overall survival of $96.4 \%$ (Fig. 1) and a 5 -year cumulative loco-regional recurrence free survival of $91.5 \%$ (Fig. 2).

Table 2 shows the univariate analysis of prognostic factors. pT, nodal status, grading, lymphangioinvasive growth, tumor diameter, ER status, PR status, and expression of Her $2 /$ neu had a prognostic value on loco-regional recurrence. At the univariate analysis of overall survival the histotype and the expression of
Table 1. Study Population Tumor-Related Factors Considered for Analysis

\begin{tabular}{|c|c|c|}
\hline Variable & Category & No. (\%) \\
\hline \multirow[t]{2}{*}{ Tumor diameter* } & $<15 \mathrm{~mm}$ & $784(50.1)$ \\
\hline & $\geq 15 \mathrm{~mm}$ & $782(49.9)$ \\
\hline \multirow[t]{4}{*}{$\mathrm{pT}^{*}$} & pT0-1 & $1356(68.8)$ \\
\hline & рT2 & $524(26.6)$ \\
\hline & pT3 & $36(1.8)$ \\
\hline & pT4 & $55(2.8)$ \\
\hline \multirow[t]{4}{*}{$\mathrm{pN}^{*}$} & pNO & $1385(72.7)$ \\
\hline & $\mathrm{pN} 1$ & $354(18.6)$ \\
\hline & $\mathrm{pN} 2$ & $119(6.2)$ \\
\hline & $\mathrm{pN3}$ & $48(2.5)$ \\
\hline \multirow[t]{3}{*}{ Histotype $^{*}$} & Ductal & $1478(74.4)$ \\
\hline & Lobular & $214(10.8)$ \\
\hline & Other & $294(14.8)$ \\
\hline \multirow{2}{*}{ Estrogen receptors* } & Negative & $275(15.0)$ \\
\hline & Positive & $1556(85)$ \\
\hline \multirow[t]{2}{*}{ Progesterone receptors ${ }^{\star}$} & Negative & $427(23.1)$ \\
\hline & Positive & 1419 (76.9) \\
\hline \multirow[t]{2}{*}{ Grading* } & G1-2 & $1379(75.4)$ \\
\hline & G3 & 449 (24.6) \\
\hline \multirow{2}{*}{ Her2/neu* } & Overexpressed & 569 (36.5) \\
\hline & Not expressed & 989 (63.5) \\
\hline \multirow[t]{2}{*}{$\mathrm{Ki} 67^{*}$} & $<20 \%$ & 777 (49.9) \\
\hline & $\geq 20 \%$ & $779(50.1)$ \\
\hline \multirow[t]{2}{*}{ p53* } & Overexpressed & $857(56.6)$ \\
\hline & Not expressed & $658(43.4)$ \\
\hline \multirow[t]{2}{*}{ Lymphoangioinvasive growth* } & Absent & $422(76.2)$ \\
\hline & Present & $132(23.8)$ \\
\hline
\end{tabular}

*Data not available for all patients.

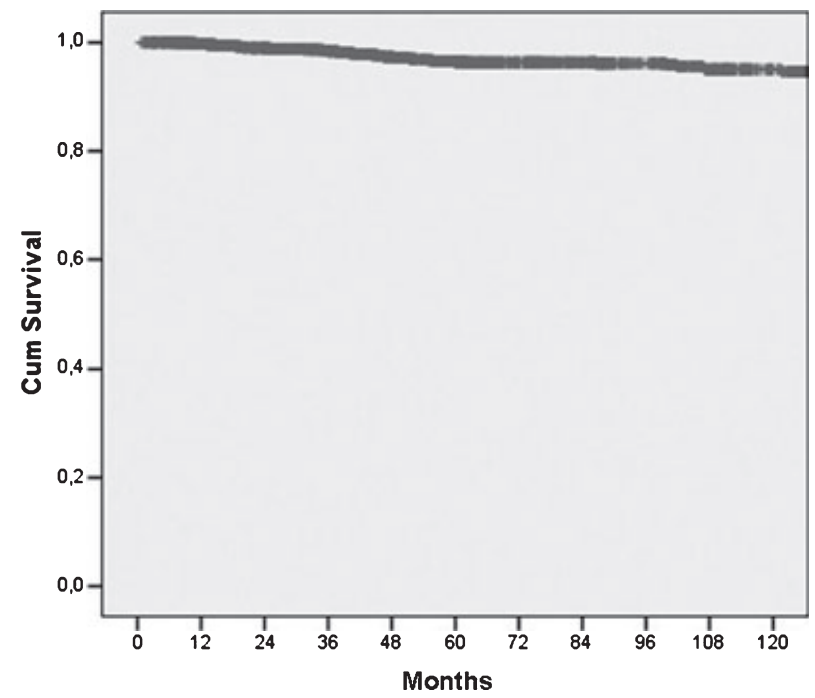

Figure 1. Cumulative overall survival for study patients.

Ki67 also were associated with outcome (but not the lymphangioinvasive growth).

In the multivariate analysis, reported in Table 3, grading remained the only independent predictor of loco-regional recurrences. With regard to overall survival, the Cox model selected grading along with 


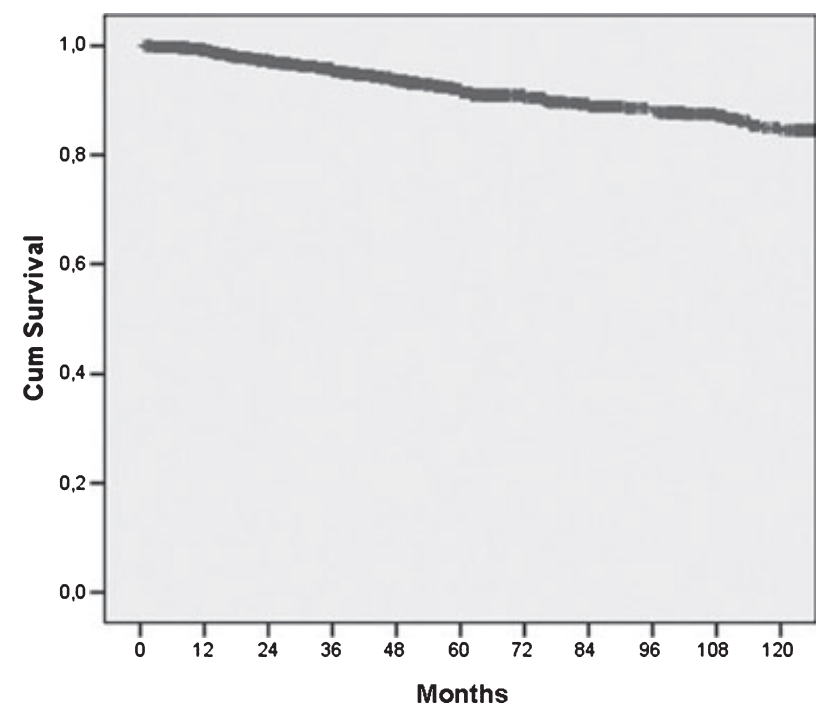

Figure 2. Cumulative loco-regional recurrence free survival for study patients.

nodal status and PR status as statistically significant independent prognostic factors.

\section{DISCUSSION}

The revolution of breast cancer treatment during the past decades has led to the progressive reduction of the surgical extent $(1-4,15,16)$. Consequently, the quality of life has improved and women are now more motivated to follow screening programs for early diagnosis of the disease. The most relevant problem in breast-conserving surgery remains the loco-regional recurrence, which can nullify the aim of conservation for subsequent mastectomy.

In the present series, we verify the predictive factors of loco-regional recurrence and survival in a large series of patients treated by surgery. In this all-stages patients sample we observed a low incidence of locoregional recurrences $(8.5 \%$ at 5 years). This important result highlights the clear improvement of the surgical approach in local control obtained in the last few years. With this regard, the distinction between true loco-regional recurrences and new primary tumors arising in the ipsilateral breast is important, since they may have different biologic behavior and prognosis and a true recurrence might denote a persistent, radioresistant, drug-insensitive and potentially more dangerous disease $(17,18)$.

Even if local failure has been linked to an increased risk of distant metastases and death (5-11), in our study the 5-year cumulative rate of loco-regional recurrences was significantly higher than 5 -year rate of cancer-related death $(8.5 \%$ versus $3.6 \%)$. There-
Table 2. Univariate Analysis
Predictive Factors for Events of

\begin{tabular}{|c|c|c|c|c|c|}
\hline Variable & Category & $\begin{array}{l}\text { 5-year loco-regional } \\
\text { recurrence free } \\
\text { survival }(\%)\end{array}$ & $p$-value & $\begin{array}{l}\text { 5-year overall } \\
\text { survival } \\
(\%)\end{array}$ & $\mathrm{p}$-value \\
\hline \multirow[t]{2}{*}{ Tumor diameter } & $<15 \mathrm{~mm}$ & 96.0 & $<0.001$ & 98.5 & 0.004 \\
\hline & $\geq 15 \mathrm{~mm}$ & 89.0 & & 95.6 & \\
\hline \multirow[t]{4}{*}{ pT } & pT0-1 & 95.7 & $<0.001$ & 99.0 & $<0.001$ \\
\hline & рT2 & 86.3 & & 93.9 & \\
\hline & pT3 & 75.3 & & 85.4 & \\
\hline & pT4 & 74.9 & & 86.9 & \\
\hline \multirow[t]{4}{*}{$\mathrm{pN}$} & pNO & 94.5 & $<0.001$ & 98.5 & $<0.001$ \\
\hline & pN1 & 92.0 & & 95.8 & \\
\hline & pN2 & 77.8 & & 90.6 & \\
\hline & pN3 & 52.3 & & 71.9 & \\
\hline \multirow[t]{3}{*}{ Histotype } & Ductal & 91.1 & 0.168 & 95.6 & 0.018 \\
\hline & Lobular & 93.4 & & 98.4 & \\
\hline & Other & 92.5 & & 98.7 & \\
\hline \multirow{2}{*}{$\begin{array}{l}\text { Estrogen } \\
\text { receptors }\end{array}$} & Negative & 84.9 & 0.021 & 92.6 & 0.002 \\
\hline & Positive & 92.4 & & 97.2 & \\
\hline \multirow{2}{*}{$\begin{array}{l}\text { Progesterone } \\
\text { receptors }\end{array}$} & Negative & 85.6 & 0.002 & 92.2 & $<0.001$ \\
\hline & Positive & 93.2 & & 98.0 & \\
\hline \multirow[t]{2}{*}{ Grading } & G1-2 & 94.2 & $<0.001$ & 97.9 & $<0.001$ \\
\hline & G3 & 82.4 & & 91.1 & \\
\hline \multirow[t]{2}{*}{ Her2/neu } & Overexpressed & 87.7 & 0.034 & 94.7 & 0.052 \\
\hline & Not expressed & 93.9 & & 97.4 & \\
\hline \multirow[t]{2}{*}{ Ki67 } & $<20 \%$ & 93.9 & 0.057 & 98.0 & 0.016 \\
\hline & $\geq 20 \%$ & 90.1 & & 95.1 & \\
\hline \multirow[t]{2}{*}{ p53 } & Overexpressed & 91.7 & 0.951 & 96.3 & 0.760 \\
\hline & Not expressed & 93.3 & & 97.0 & \\
\hline \multirow[t]{2}{*}{ Lymphoangioinvasive growth } & Absent & 92.8 & 0.016 & 94.0 & 0.07 \\
\hline & Present & 75.3 & & 91.2 & \\
\hline
\end{tabular}




\begin{tabular}{llll}
\hline Variable & Category & Loco-regional recurrence & Cancer-related \\
& & $\mathrm{HR}(95 \% \mathrm{Cl})$ & death HR $(95 \% \mathrm{Cl})$ \\
Grading & $\mathrm{G} 1-2$ & 1 & 1 \\
$\mathrm{pN}$ & $\mathrm{G} 3$ & $5.321(1.387-20.424)$ & $2.895(1.187-7.063)$ \\
& $\mathrm{pN}$ & - & 1 \\
Progesterone & $\mathrm{pN}+$ & - & $2.665(1.141-6.226)$ \\
receptors & Negative & - & 1 \\
& Positive & - & $0.246(0.096-0.632)$ \\
\hline
\end{tabular}

Table 3. Multivariate Analysis of Predictive Factors for Events

$\mathrm{HR}$, hazard ratio; $\mathrm{Cl}$, confidence interval.

fore, loco-regional recurrence should not be considered as a failure of surgical approach (conservative or not) or responsible for systemic progression by itself: in fact, previous trials have shown that patients with a high incidence of local recurrences have the same survival rate as patients with a low local recurrence rate $(1,2)$. Hence, loco-regional recurrence can be evaluated as a marker of tumor aggressiveness and a predictive factor for distant metastases and death $(6,11,19-21)$, but as a condition still susceptible of cure.

By identification of loco-regional recurrence tumorrelated predictors, we could identify a subset of patients, who might be curatively treated with a further therapy (surgical or not), allowing a good local control.

According to the results of univariate analysis, the loco-regional recurrence and the distant recurrence (or cancer-related death) shared some prognostic factors among the tumor characteristics, such as $\mathrm{pT}$, nodal status, grading, tumor diameter, ER status, PR status, and overexpression of Her2/neu. In contrast, histotype and an expression of Ki67 were predictors of systemic progression only, specifically denoting a greater metastatic capacity.

Similarly, the multivariate models for loco-regional recurrence free survival and overall survival were different. In fact, for loco-regional recurrence free survival the Cox regression selected the grading as the only independent prognostic factor, like a more specific marker of local aggressiveness. In contrast, for overall survival the regression model selected grading along with nodal status and PR status: the nodal status as a measure of invasive potential and the PR status as a relevant feature for therapy.

Last result highlights a limitation of our study: in fact, the sample included patients underwent adjuvant (and neo-adjuvant) therapy which could favorably affected prognosis and, hence, our analysis results.

Further limitation of this study regards the duration of follow-up with the subsequent (not ever reliable) actuarial survival rates. A substantial proportion of events occurred after 5 years of follow-up, supporting the need for longer follow-up $(1,6,11)$.

In conclusion, loco-regional recurrences after breast cancer surgery are not frequent events. They are markers of tumor aggressiveness and predictor of an increased likelihood of cancer-related death. However, loco-regional recurrence and systemic tumor progression are partially independent events, since some prognostic factors differ.

\section{REFERENCES}

1. Veronesi U, Cascinelli N, Mariani L, et al. Twenty-year follow-up of a randomized study comparing breast-conserving surgery with radical mastectomy for early breast cancer. N Engl J Med 2002;347:1227-32.

2. Fisher B, Anderson S, Bryant J, et al. Twenty-year follow-up of a randomized trial comparing total mastectomy, lumpectomy, and lumpectomy plus irradiation for the treatment of invasive breast cancer. N Engl J Med 2002;347:1233-41.

3. Poggi MM, Danforth DN, Sciuto LC, et al. Eighteen-years results in the treatment of early breast carcinoma with mastectomy versus breast conservation therapy: the National Cancer Institute Randomized Trial. Cancer 2003;98:697-702.

4. van Dongen JA, Bartelink H, Fentiman IS, et al. Randomized clinical trail to assess the value of breast-conserving therapy in stage I and II breast cancer, EORTC 10801 trail. J Natl Cancer Inst Monogr 1992;11:15-8.

5. Touboul E, Buffat L, Belkacemi Y, et al. Local recurrences and distant metastases after breast-conserving surgery and radiation therapy for early breast cancer. Int J Radiat Oncol Biol Phys 1999;43:25-38.

6. Wapnir IL, Anderson SJ, Mamounas EP, et al. Prognosis after ipsilateral breast tumor recurrence and locoregional recurrences in five National Surgical Adjuvant Breast and Bowel Project nodepositive adjuvant breast cancer trials. J Clin Oncol 2006;24:202837.

7. Fisher B, Wickerham DL, Deutsch M, Anderson S, Redmond C, Fisher ER. Breast tumor recurrence following lumpectomy with and without breast irradiation: an overview of recent NSABP findings. Semin Surg Oncol 1992;8:153-60.

8. Komoike Y, Akiyama F, Iino Y, et al. Ipsilateral breast tumor recurrence (IBTR) after breast-conserving treatment for early breast cancer: risk factors and impact on distant metastases. Cancer 2006;106:35-41.

9. Freedman GM, Fowble BL. Local recurrence after mastectomy or breast-conserving surgery and radiation. Oncology 2000;14:1561-81. 
10. Chen SL, Martinez SR. The survival impact of the choice of surgical procedure after ipsilateral breast cancer recurrence. Am J Surg 2008;196:495-9.

11. Anderson SJ, Wapnir I, Dignam JJFisher B, et al. Prognosis after ipsilateral breast tumor recurrence and locoregional recurrences in patients treated by breast-conserving therapy in five National Surgical Adjuvant Breast and Bowel Project protocols of node-negative breast cancer. J Clin Oncol 2009;27:2466-73.

12. Kaplan EL, Meier P. Nonparametric estimation from incomplete observations. J Amer Statist Assn 1958;53:457-81.

13. Mantel N. Evaluation of survival data and two new rank order statistics arising in its consideration. Cancer Chemother Rep 1966;50:163-70.

14. Cox DR. Regression models and life-tables (with discussion). J Roy Stat Soc 1972;34:187-220.

15. Luini A, Gatti G, Galimberti V, et al. Conservative treatment of breast cancer: its evolution. Breast Cancer Res Treat 2005;94:195-8.

16. Veronesi U, Paganelli G, Viale G, et al. Sentinel-lymph-node biopsy as a staging procedure in breast cancer: update of a randomised controlled study. Lancet Oncol 2006;7:983-90.
17. Nashimura S, Takahashi K, Akiyama F, et al. Classification of ipsilateral breast tumor recurrence after breast-conserving therapy: new primary cancer allows a good prognosis. Breast Cancer 2005;12:112-7.

18. Luini A, Gatti G, Zurrida S, et al. The evolution of conservative approach to breast cancer. Breast 2007;16:120-9.

19. Clark RM, Whelan T, Levine M, et al. Randomized clinical trail of breast irradiation following lumpectomy and axillary dissection for node-negative breast cancer: an update. Ontario clinical oncology group. J Natl Cancer Inst 1996;88:1659-64.

20. Kurtz JM, Amalric R, Brandone H, et al. Local recurrence after breast-conserving surgery and radiotherapy. Frequency, time course, and prognosis. Cancer 1989;63:1912-7.

21. Gentilini O, Botteri E, Rotmensz N, et al. When can a second conservative approach be considered for ipsilateral breast tumour recurrence? Ann Oncol 2007;18:468-72. 